Proceedings of the 2009 Winter Simulation Conference

H.H.Wang, B. Hu, and G. Y. Jiang, eds.

\title{
SIMULATION OF PROJECT-BASED ORGANIZATIONAL DESIGN IN CHINA: FROM THE PERSPECTIVE OF CONTEXTUAL INTERACTIONS
}

\author{
Huanhuan Wang \\ $\mathrm{Bin} \mathrm{Hu}$ \\ Guoyin Jiang \\ Sch. of Management \\ Huazhong University of Sci. and Tech. \\ Luoyu Road 1037, Wuhan, 430074, P.R.CHINA
}

\begin{abstract}
The project-based organizations engaging in engineering consultancy are at the early stage in China. For the manager of China, how to conduct the organization design for them according to contextuality that characterizes the conditions of China is an important issue. First, the factors that affect the performance of this type of the project-based organization of China are analyzed. Then, the organizational design model that has both the advantages of NK model and the ones of complementarity framework is proposed. The impacts of the interactions among the design dimensions of organization, capability to gain resource and turbulence of the environment on the organizational design are researched with simulation approach. Furthermore, the qualitative demonstration of the model is done with data and materials gathered from the actual cases. Last, the implications of the results are put forward.
\end{abstract}

\section{INTRODUCTION}

The design dimensionalities or activities of organization are interdependent. The fit and consistency (Drazin and Van de Ven 1985) among an organization's activities which is viewed as contextuality, are one of the important factors which ensure the organization the competitive advantages (Porter and Siggelkow 2008). Since the mid-20th century, management paradigm has been changing from the functional and hierarchical, almost already adopted in the first half of the century, to project and process-based organization (Daft 2001). The singularity of goals and outputs of the project results in the versatile control model for the project-based organization (PBO). And the versatile control model make the governance and operational control decoupled (Turner and Keegan 1999). In such a situation, it's important that we conduct organization design for PBOs based on the contexuality.

The construction project is an important type of project-based organization. In order to line with the international practice and under the guidance of Document No. 20 of the State Council of China in the year 2004, the Chinese government has made great efforts to develop engineering consultancy industry. The project-based organizations engaging in the engineering consultancy called EC-PBO in short are at the early stage of the development in China. Because of the characters of the Chinese society, the Chinese EC-PBOs can't copy the given patterns of organization design suitable for the developed country and must configure the activities according to the contextuality determined by the Chinese own reality and characteristics.

There are two structured ways to analyze the contextuality (Porter and Siggelkow 2008). One is agent-based simulation modeling using the NK model (Kauffman 1993), the other is the complementarity framework (Milgrom and Roberts 1995). Although agent-based modeling has been applied to the organization theory and the organizational behavior (Carley 1994, Carley 1996, Carley 2002, Gilbert and Conte 1995, Gong and $\mathrm{Hu} 2006$, Wu and $\mathrm{Hu}$ 2007), the former mainly focuses on analysis of the results of contextuality among the activities. The degree of independence among the activities can be expressed only by the two parameters $\mathrm{N}$ and $\mathrm{K}$, which is the advantage compared with the other mathematic method. Early NK model is mainly used to find the activities configuration which can get to the local or global optimal value of the performance landscape, or to search for the path arriving to the optimal performance (Levinthal 1997). Recently, the use of NK models are mainly of the modeling of organizational structure design (Rivkin and Siggelkow 2003, Siggelkow and Rivkin 2005, Siggelkow and Rivkin 2006). The limitation of NK model is that the type of interaction can't be reflected. The latter can represents the type of interactions, yet has not the advantage of simplicity in representing the degree of interdependence possessed by the NK model. And the latter focuses on identifying the activities which are complements exactly. 
In this paper, we aim to explore how to design the project-based organization of the engineering consulting industry in China according to the contextuality. In section 2 , the design elements and their interdependencies are analyzed. In the section 3, we elaborate the model. The model proposed shows off the advantages both NK model and complementarity framework, on the other hand, the model also demonstrates the contexuality determined by the environment of China. This study relies on a computer simulation model using an agent-based simulation. We then give the overview of the simulation process in section 4. In section 5, the results of the model are analyzed in detail and the implications of the results are put forward. Furthermore, the qualitative demonstration of the model is done with data and materials gathered from the actual cases in section 5 also. Lastly, we make a summary of works of this paper.

\section{DESIGN ELEMENTS AND THEIR INTERDEPENDENCIES}

Through our investigation and study, we found that (a) size, (b) formalization and regularization, (c) form of information processing referring to decentralization or centralization and (d) incentive system are the main design elements or activities which need to be paid attention to by EC-PBO of China. Besides the above structure dimensions or formal elements of organization design, (e) capability to gain resource and (f) turbulence of the environment are the other two informal elements of EC-PBO. Institution constrains organizational design activity in the light of institutional perspective (Tannenbaum and Cooke 1980). The property right and the ambiguity of the property rights of EC-PBO, caused by the structural transformation of the economy in China, are the two important attributes constraining the institutional environment of China. Therefore the EC-PBOs with different attributes will have different channels for projects or capability for obtaining the projects. So, the capability mainly refers to the capability of resource gaining determined by the non-economic factors. Meanwhile, the environment is turbulent due to the fast development of the technology, law administrative rules and regulations, and global competition, etc. Therefore, the main topic of this paper is on how to configure the four formal design elements of ESC-PBO based on contextuality by taking into account the latter two factors. The above design elements of EC-PBO and their interdependencies are as shown in Figure 1.

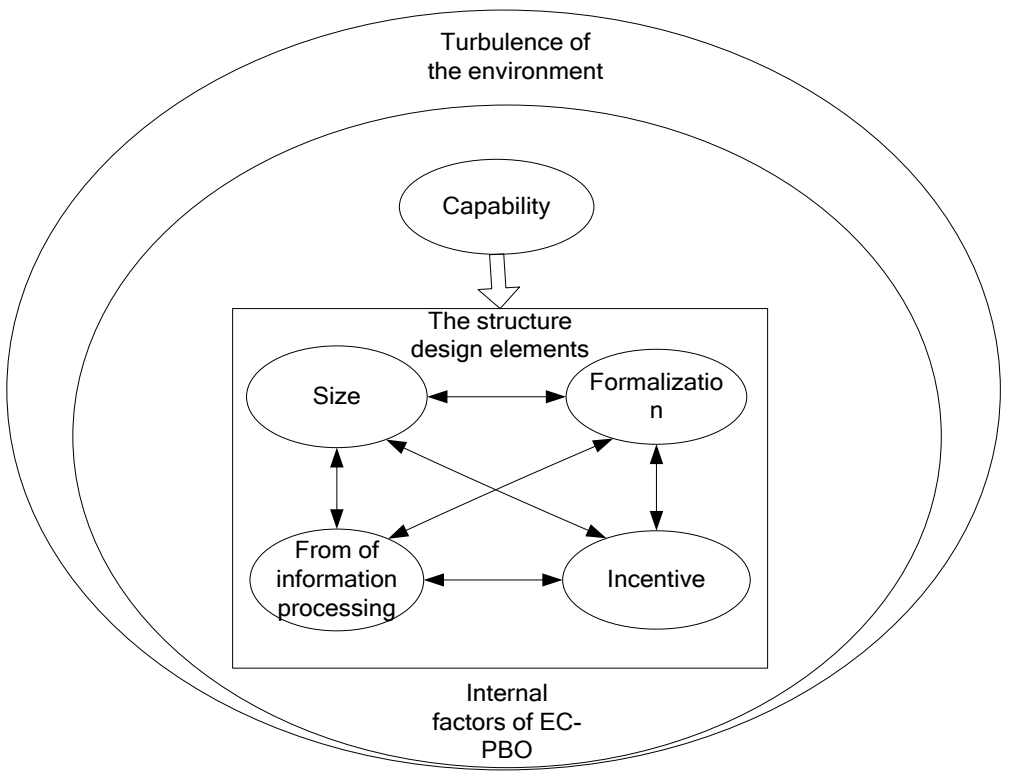

Figure 1: Design elements and their interdependencies

\section{MODELING}

First, we introduce the NK model and complementarity framework. Then the model of EC-PBO design is proposed. Finally, values are assigned and the specification of values is give to the design activities of EC-PBO based on the requirements of the design model of EC-PBO.

\subsection{Overview of the NK Model and Complementarity Framework}

In the 1990's, Kauffman proposed the NK model building on the fitness landscapes theory proposed by Wright (Wright 1931). Although the NK model was originated from the biology research, many scholars including Kauffman adopted the NK 
model to study the economic and management problems. In the NK model, N denotes the number of activities; K denotes the degree of interdependence among the activities. Generally, each of activities takes only one of two values, which can be coded as 0 and 1, for example, size of organization is either large(0) or small(1). Thus, the total number of organizational types is $2^{N}$. The contribution of each of activities, denoted by $f_{i}\left(x_{i}^{k}\right)$ determined by a random draw from the uniform distribution $\mathrm{u}[0,1]$, is dependent on the configuration of itself and the other $\mathrm{K}$ related activities. And $F(X)$, the overall performance of the one type of organization, is $N^{-1} \sum_{i}^{N} f_{i}\left(x_{i}^{k}\right)$. Therefore, the contextuality implies that the contribution of each activity is dependent on how $\mathrm{K}$ related activities configured. The central aspect of modeling is to find the optimal configuration of $\mathrm{N}$ activities whose performance is the greatest. The type of interactions between the two activities can't be expressed in the NK model because the value of contributions is assigned randomly.

The types of interactions are defined elaborately in the complementarity framework built on the supermodularity theory worked by Topkis (Topkis 1978). According to the complementarity framework, if the profit of improving two activities together at the same time is more than separately improving one of the two activities, the two activities are said to be complements, otherwise substitutes. However, whether the two activities are complements or substitutes maybe depends on the configuration of the other activities and thus the two activities are said to be contextual. However, the complementarity framework does not have the merit of the NK model in which the degree of interdependence can be controlled with one parameter K simply.

To sum up the above arguments, the approach to integrate the advantages of both the NK model and the complementarity framework is very useful in researching on the organization design. Some suggestions over this approach are given by Porter and Siggelkow (Porter and Siggelkow 2008) and our model is based on their work.

\subsection{Design Model of EC-PBO}

We first introduce our notation, then introduce the hypothesis and constrains of the model.

- Let $X=\bigcup_{i=1}^{n} x_{i}$ denote the set of $n$ activities. Define $C_{n}^{i}(X)$ to be the combination of $i$ activities in X.

- Let $x_{i}^{2}, x_{i}^{1} \in R$ and $x_{i}^{2}>x_{i}^{1}$. Then the set $\left\{x_{i}^{1}, x_{i}^{2}\right\}$ denotes the state set of activity $x_{i}$.

A function $F\left(x_{k}, x_{l}, X_{\backslash k l}\right): R^{n} \rightarrow R$ is supermodular if the following conditions are satisfied:

- $\quad F\left(x_{k}^{2}, x_{l}^{2}, X_{\backslash k l}\right)-F\left(x_{k}^{1}, x_{l}^{2}, X_{\backslash k l}\right) \geq F\left(x_{k}^{2}, x_{l}^{1}, X_{\backslash k l}\right)-F\left(x_{k}^{1}, x_{l}^{1}, X_{\backslash k l}\right)\left(x_{\backslash k l} \in R^{n-2}\right)$;

- The above inequation is fulfilled for all $x_{k}^{2}>x_{k}^{1}, x_{l}^{2}>x_{l}^{1}$ and

- for all values or combination of $X_{\backslash k l}$.

If the function $F\left(x_{k}, x_{l}, X_{\backslash k l}\right)$ is supermodular, activities $x_{k}$ and $x_{l}$ are complements. But if $F\left(x_{k}^{2}, x_{l}^{2}, X_{\backslash k l}\right)-F\left(x_{k}^{1}, x_{l}^{2}, X_{\backslash k l}\right) \leq F\left(x_{k}^{2}, x_{l}^{1} \leq, X_{\backslash k l}\right)-F\left(x_{k}^{1}, x_{l}^{1}, X_{\backslash k l}\right)$ and the other two conditions are still the same, activities $x_{k}$ and $x_{l}$ are substitutes.

According to the above arguments, we propose the performance function of the EC-PBO as followed:

$$
F(X)=\sum_{i=1}^{n} \sum_{j=1}^{b} a_{i j} C_{n}^{i}(X) \text { where } b=\frac{n !}{(n-i) ! i !}
$$

In our model, $\left\{x_{i}^{1}, x_{i}^{2}\right\}=\{0,1\}$. That practice meets the requirements of the proposed model, that is to say, it meets the state of variable which can be sorted with some kind of form in complementarity framework, and the state of variable is one of only two discrete values, 0 and 1 in NK model. .

We can create the contextuality of the activities by choosing appropriate values or distribution for $a_{i j}$. For example, if $\mathrm{N}=3, F(X)=a_{11} x_{1}+a_{12} x_{2}+a_{13} x_{3}+a_{21} x_{1} x_{2}+a_{22} x_{1} x_{3}+a_{23} x_{2} x_{3}+a_{31} x_{1} x_{2} x_{3}$. when $a_{2 \mathrm{j}}=a_{31}=0(j \in\{1,2,3\})$, all activities are independent, thus, we can create the performance landscapes by drawing random values for $a_{1 \mathrm{j}}(j \in\{1,2,3\})$ similar to the ones of $\mathrm{K}=0$ created by the NK model. Considering the cross-partial derivative of $x_{1}, x_{2}$ and $x_{3}, \frac{\partial^{3} F}{\partial x_{1} \partial x_{2} \partial x_{3}}=a_{31}$, if $a_{31}>0, x_{1}$ ,$x_{2}$ and $x_{3}$ are complements. Yet, if $0<a_{2 \mathrm{j}}<1$ and $a_{31}<-1$, all activities are contextual. In this case, we consider the crosspartial derivative of $x_{1}$ and $x_{2}, a_{21}+a_{31} x_{3}$. It equals $a_{21}$ if $x_{3}=0$. Since $0<a_{2 j}<1, x_{1}$ and $x_{2}$, are complements. However, if $x_{3}=1$, since $0<a_{2 \mathrm{j}}<1$ and $a_{31}<-1, x_{1}$ and $x_{2}$, are substitutes. Since each of the activities or variables takes two discrete val- 
ues, 0 and 1, the equation (1) in the model meets the requirements both the NK model and the complementarity framework in which the values of the variables can be sorted in certain order.

In order to represent the capability of the EC-PBO and turbulence of the environment, $\mu$, and $\sigma$, the other two variables is introduced.

Let $\mu \geq 0$ and $\mu \in R$. Then, the greater $\mu$ is, the stronger the capability the EC-PBO has.

Let $\sigma \geq 1$ and $\sigma \in R$. Then, the greater $\sigma$ is, the more turbulent the environment is.

Built on the equation (1), the design model of the EC-PBO is proposed as followed finally:

$$
F(X, e)=\left(\sum_{i=1}^{n} \sum_{j=1}^{b} a_{i j} C_{n}^{i}(X)+\phi(e)\right) /\left(\sum_{i=1}^{n} C_{n}^{i}+1\right), \quad \text { where } b=\frac{n !}{(n-i) ! i !}, \quad e \sim N(\mu, \sigma)
$$

In the equation (2), $e$ is a random number generated from a normal distribution $N(\mu, \sigma)$ and $\phi(e)$ is the area to the left of $e$ under the standard normal distribution function, that is to be denote the cumulative distribution function of the standard normal(see Figure 2). As shown in Figure 2, since $\phi(e)$ is a random number between 0 and 1 , to ensure the value of the performance of the EC-PBO is between 0 and $1, \mathrm{~F}(\mathrm{X}, \mathrm{e})$ is the average of all the random number in equation (2).

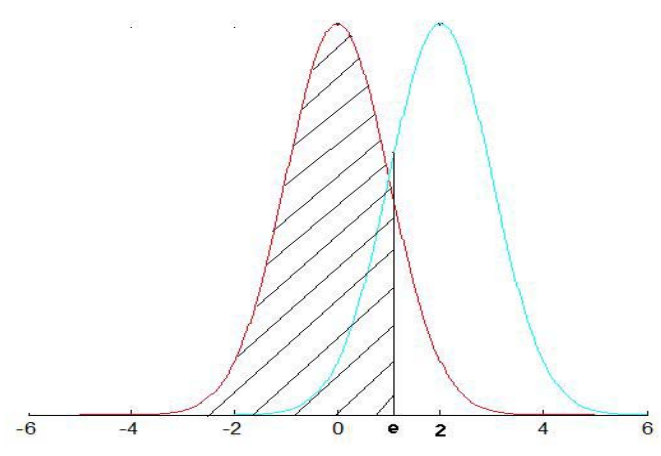

Figure 2: Value of $\phi(e)$

\subsection{State Description of the Variables}

Since the structured variables that have a significant effect on the EC-PBOs and among them size, formalization, form of information processing and incentive system differentiate EC-PBOs principally, we mainly consider the above four structured variables in the model and neglect the other variables or take the other ones as constants. And this scheme meets the requirements or constrains of the model. We will explain the values of the variables according to the model in detail in this section.

Since the 1960's, the management paradigm has been shifted from mechanical one emphasizing the efficiency to the organic one. Along with this shift, there has been a shift in organization design from the bureaucratic, functional approach to the project-based approach. Therefore, we can see that the size of many organizations has been decreasing each year, even the big enterprise has adopted this form of project-based organization so as to obtain the advantages that the small businesses have. However, in order to respond to the rapid changes in the environment, the businesses usually need non-formal operation and decentralization in information processing usually. At meantime, incentives have played a big role in the development of the businesses and they have been given the greater attention, for example, the application of high performance work practices (HPWPs). These changes are the direction of organizational design in the future. So, according to the direction of organization development, we can sort order for the state of each structure variable, which is denoted by the value 0 or 1 , as shown in Table 1. 
Wang, Hu, and Jiang

Table 1: Description of the structure variables of the EC-PBO

\begin{tabular}{llll}
\hline Variable & Corresponding design element & \multicolumn{2}{l}{ Description for the states of variable } \\
\cline { 3 - 4 } & & 0 & 1 \\
\hline$x_{1}$ & Size & large & small \\
$x_{2}$ & Formalization & formal & Non-formal \\
$x_{3}$ & Form of information processing & centralization & decentralization \\
$x_{4}$ & Incentive & no & yes \\
\hline
\end{tabular}

In order to evaluate the elements or dimensions of organization design, we can conduct questionnaire survey on the organizational design. Then we can process the data representing the design elements formally. If the value of a variable from the questionnaire survey is greater than the average, we will take value "1" for corresponding design element; otherwise we will take the value " 0 ".

According to the organization theory, a small business is usually non-formal, and is combined with decentralized decision making. The recent study demonstrates that the HPWPs are positively correlated with the decentralized decision making and horizontal organization.

Based on the above analysis, $x_{1} x_{2} x_{3} x_{4}$ in the Table 1 are complements. And this argument is the universal practice or conventional wisdom. Thus, in model (2), $N=4, a_{2 j}>0, a_{3 j}>0, a_{4 j}>0$ and $\mathrm{K}=3$ obviously.

\section{OVERIEW OF THE SIMULATION APPROACH}

As we know, EC-PBOs have four design variables. Each variable is affected by the configuration of the other 3 variables, that is to say $\mathrm{K}=3$, and each variable can take one of two values, 0 and 1 . Therefore the total number of EC-PBO type will be $2^{\mathrm{k}+1}=16$, and each variable can be denoted by a four-bit string according to the configuration or combination of $x_{1} x_{2} x_{3}$ and $x_{4}$. We also know that $a_{2 j}>0, a_{3 j}>0$ and $a_{4 j}>0$. Thus, computer simulations can be conducted to determine the average performance of every type of EC-PBO obtained from the equation (2) for the same $\mu$ and $\sigma$ by assigning $a_{i j}$ a randomly drawn number from the uniform distribution, $\mathrm{U}(0,1)$, over 500 unit interval and then by changing the value of $\mu$ and $\sigma$ and repeating the above process. Finally, we obtain the expected performance of every type of EC-PBOs with different $\mu$ in the different environment $\sigma$ and compare them from different perspective to study the effects of contextuality of variables, capability and turbulence of the environment on the organizational design of the EC-PBO respectively.

\section{RESULTS AND VALIDATION}

\section{$5.1 \quad$ Results}

An EC-PBO denoted by a four-bit string with the combination of the four structure variables, for example, "0000", which means that $x_{1} x_{2} x_{3} x_{4}$ all take 0 , is one type of the EC-PBO and 1111, which means that $x_{1} x_{2} x_{3} x_{4}$ all take 1, is another type of EC-PBO. We know that since the four structure variables of the EC-PBO are complements, we can conclude that if the capability of the EC-PBO and turbulence of the environment are neglected, what all values of these four variables are 1 is the best design. Three out of four variables are 1 is the second best design. Of course, the more 1 in these variables are, the better result we would get. However, if the capability of the EC-PB and turbulence of the environment are considered, is the above conclusion untenable? The results from the computer simulation have provided some useful implications about the effect of these two variables on the organizational design.

\subsubsection{Effect of Capability}

In order to explore the role of capability on the EC-PBO, we place 16 types of EC-PBO in the same environment, which means that $\sigma$ of all EC-PBOs are the same and equal to 1 . The performance values of 16 types of EC-PBOs all with the same value $\sigma(\sigma=1)$ are shown at Table 2 and the comparison of performance between some EC-PBOs is given in Figure 3. As shown in Table 2 and Figure 3, we see that the capability of the EC-PBO has a notable impact on the organization design compared with the conventional wisdom concluded from the overview of the papers and the organization theory. That is to say, if we do not consider the capability, the performance of the EC-PBO can be improved markedly because of the complement correlation among $x_{1}-x_{4}$. However, if considering the capability, low level of capability may lessen the complement 
correlation. As shown in Figure 3, the performance of "0000" type of EC-PBO under the high capability $(\mu=8)$ is more than that of " 0010 " under the low capability $(\mu=0)$, while " 0010 " type of EC-PBO under the high capability $(\mu=8)$ has the similar performance with " 0011 " under the low capability $(\mu=0)$.

Table 2: Performance of all kinds of EC-PBO when $\sigma=1$

\begin{tabular}{ccccc}
\hline \multirow{2}{*}{$\begin{array}{c}\text { Type of EC- } \\
\text { PBO }\end{array}$} & $\mu=0$ & $\mu=1$ & $\mu=5$ & $\mu=8$ \\
\cline { 2 - 5 } 0000 & $7.052 \mathrm{E}-02$ & $1.132 \mathrm{E}-01$ & $1.428 \mathrm{E}-01$ & $1.429 \mathrm{E}-01$ \\
0001 & $7.307 \mathrm{E}-02$ & $1.116 \mathrm{E}-01$ & $1.428 \mathrm{E}-01$ & $1.429 \mathrm{E}-01$ \\
0010 & $7.309 \mathrm{E}-02$ & $1.116 \mathrm{E}-01$ & $1.428 \mathrm{E}-01$ & $1.429 \mathrm{E}-01$ \\
0100 & $7.307 \mathrm{E}-02$ & $1.116 \mathrm{E}-01$ & $1.428 \mathrm{E}-01$ & $1.429 \mathrm{E}-01$ \\
1000 & $7.307 \mathrm{E}-02$ & $1.116 \mathrm{E}-01$ & $1.428 \mathrm{E}-01$ & $1.429 \mathrm{E}-01$ \\
0011 & $1.472 \mathrm{E}-01$ & $1.780 \mathrm{E}-01$ & $2.155 \mathrm{E}-01$ & $2.133 \mathrm{E}-01$ \\
0101 & $1.472 \mathrm{E}-01$ & $1.780 \mathrm{E}-01$ & $2.155 \mathrm{E}-01$ & $2.133 \mathrm{E}-01$ \\
1001 & $1.472 \mathrm{E}-01$ & $1.780 \mathrm{E}-01$ & $2.155 \mathrm{E}-01$ & $2.133 \mathrm{E}-01$ \\
0110 & $1.472 \mathrm{E}-01$ & $1.780 \mathrm{E}-01$ & $2.155 \mathrm{E}-01$ & $2.133 \mathrm{E}-01$ \\
1010 & $1.472 \mathrm{E}-01$ & $1.781 \mathrm{E}-01$ & $2.155 \mathrm{E}-01$ & $2.133 \mathrm{E}-01$ \\
1100 & $1.472 \mathrm{E}-01$ & $1.781 \mathrm{E}-01$ & $2.155 \mathrm{E}-01$ & $2.133 \mathrm{E}-01$ \\
0111 & $2.838 \mathrm{E}-01$ & $3.249 \mathrm{E}-01$ & $3.575 \mathrm{E}-01$ & $3.543 \mathrm{E}-01$ \\
1011 & $2.839 \mathrm{E}-01$ & $3.249 \mathrm{E}-01$ & $3.575 \mathrm{E}-01$ & $3.543 \mathrm{E}-01$ \\
1101 & $2.838 \mathrm{E}-01$ & $3.249 \mathrm{E}-01$ & $3.575 \mathrm{E}-01$ & $3.544 \mathrm{E}-01$ \\
1110 & $2.838 \mathrm{E}-01$ & $3.249 \mathrm{E}-01$ & $3.575 \mathrm{E}-01$ & $3.543 \mathrm{E}-01$ \\
1111 & $4.965 \mathrm{E}-01$ & $5.379 \mathrm{E}-01$ & $5.749 \mathrm{E}-01$ & $5.756 \mathrm{E}-01$ \\
\hline
\end{tabular}

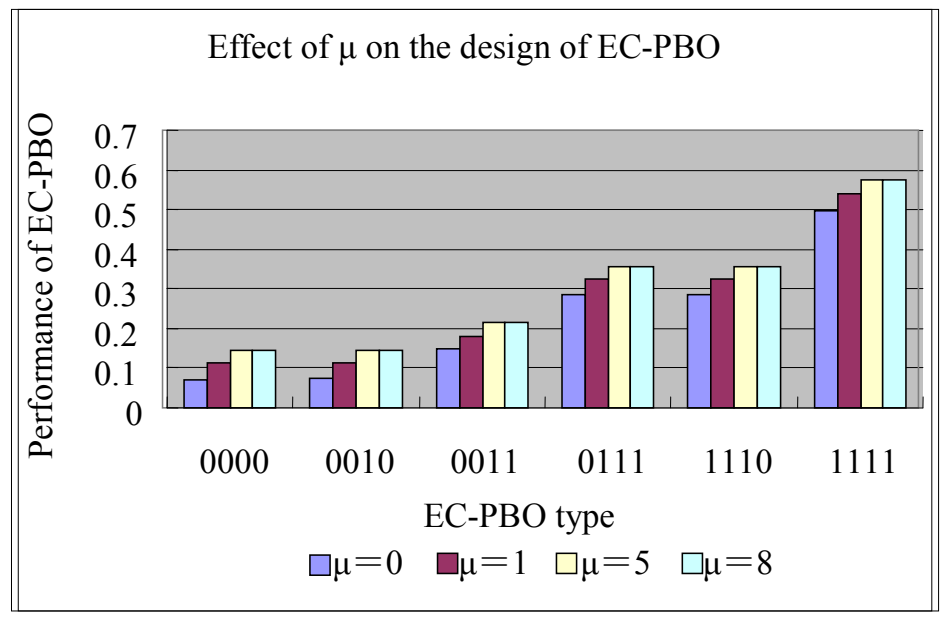

Figure 3: Effect of the capability on the design of part of EC-PBO

The result clearly shows the importance of the capability of the EC-PBO. We designed the variables of the organizational design, according to the result. Since the material or economic incentive is the main incentive means for the EC-PBO, it must be designed carefully because it has a significant impact to the profit of the project-based organization. So, if the ECPBO has higher capability, it will still achieve the anticipated performance even without any incentives. Otherwise, when the capability of the EC-PBO is low, some incentives must be adopted to incentive the members of the EC-PBO ensuring that all 
the members of the EC-PBO will share the common objective (Turner and Simister 2001). For example, if the EC-PBO has the stable channels of getting projects because of the property right advantage, this EC-PBO need not material incentive. The reason is that the EC-PBOs with the higher capability take the lower risks and transfer the share of profit to the correlated organization. Considering that difference of the capability between the EC-PBOs at early development stage, the profit of investment can be improved significantly if we could design incentive system for them according to the capability.

\subsubsection{Effect of Turbulence of the Environment}

We generate the values of the performance over the long time simulation for 16 types of EC-PBOs with different capabili$\operatorname{ty}(\mu)$ under the different environment $(\sigma)$. Figure 4 shows the performance movement of some EC-PBOs over time. As shown in Figure 4, we see that for all the type of the EC-PBOs, the performance changes very little with $\sigma$ when the EC-PBO is capable, but decreases dramatically with $\sigma$ when the EC-PBO is not capable. In terms of capability of the EC-PBO, we compute variance of performance under the different $\sigma$ for each of EC-PBO respectively, which represent the effect of capability on the stability of performance. And Table 3 lists the results. Furthermore the effect of capability and the complement correlation of the structure variables on the stability of performance are demonstrated in Table 3 and Table 4 respectively. As shown in Figure 4, we see that for all the type of the EC-PBO, the performance changes very little with $\sigma$ when the ESC-PBO is not capable $(\mu=0)$, but decreases dramatically with $\sigma$ when the EC-PBO is capable $(\mu=1,5,8)$. Besides, for 0000 and 0010 type of EC-PBO, the performance of EC-PBOs when they are capable is always better than the ones when they are not capable even though it decreases dramatically with $\sigma$ from 1 to 16 . However, for 0011 type of EC-PBO, when $\sigma=16$, the performance in all kinds of capability are similar. And so do for 0111,1110 and 1111 type of EC-PBO. The results indicate that the more turbulent the environment is, the less powerful the capability of the EC-PBO is. Yet, the complement correlation among the structure variables plays more important role on the stability of the performance for the EC-PBOs with $\sigma$ increasing.

Table 3: Effect of $\mu$ on the stability of performance

\begin{tabular}{ccccccc}
\hline \multirow{2}{*}{$\mu$} & \multicolumn{7}{c}{ EC-PBO type } \\
\cline { 2 - 7 } & 0000 & 0100 & 1100 & 0111 & 1110 & 1111 \\
\hline 0 & $2.91 \mathrm{E}-05$ & $4.51 \mathrm{E}-05$ & $4.38 \mathrm{E}-05$ & $8.07 \mathrm{E}-05$ & $8.10 \mathrm{E}-05$ & $1.49 \mathrm{E}-04$ \\
1 & $1.414 \mathrm{E}-03$ & $1.174 \mathrm{E}-03$ & $8.680 \mathrm{E}-04$ & $1.039 \mathrm{E}-03$ & $1.038 \mathrm{E}-03$ & $1.131 \mathrm{E}-03$ \\
5 & $3.983 \mathrm{E}-03$ & $4.557 \mathrm{E}-03$ & $4.379 \mathrm{E}-03$ & $3.213 \mathrm{E}-03$ & $3.214 \mathrm{E}-03$ & $4.478 \mathrm{E}-03$ \\
8 & $2.667 \mathrm{E}-03$ & $2.599 \mathrm{E}-03$ & $3.366 \mathrm{E}-03$ & $2.966 \mathrm{E}-03$ & $2.966 \mathrm{E}-03$ & $3.683 \mathrm{E}-03$ \\
\hline
\end{tabular}

Table 4: Effect of $\sigma$ on the stability of the performance

\begin{tabular}{ccccccc}
\hline \multirow{2}{*}{$\sigma$} & \multicolumn{7}{c}{ EC-PBO type } \\
\cline { 2 - 7 } & 0000 & 0100 & 1100 & 0111 & 1110 & 1111 \\
\hline 1 & $3.511 \mathrm{E}-03$ & $3.294 \mathrm{E}-03$ & $3.166 \mathrm{E}-03$ & $3.508 \mathrm{E}-03$ & $3.511 \mathrm{E}-03$ & $4.228 \mathrm{E}-03$ \\
2 & $3.631 \mathrm{E}-03$ & $3.546 \mathrm{E}-03$ & $4.036 \mathrm{E}-03$ & $3.887 \mathrm{E}-03$ & $3.887 \mathrm{E}-03$ & $4.639 \mathrm{E}-03$ \\
3 & $3.981 \mathrm{E}-03$ & $3.890 \mathrm{E}-03$ & $3.726 \mathrm{E}-03$ & $3.357 \mathrm{E}-03$ & $3.357 \mathrm{E}-03$ & $3.293 \mathrm{E}-03$ \\
4 & $3.351 \mathrm{E}-03$ & $3.414 \mathrm{E}-03$ & $2.921 \mathrm{E}-03$ & $2.873 \mathrm{E}-03$ & $2.873 \mathrm{E}-03$ & $2.946 \mathrm{E}-03$ \\
6 & $2.094 \mathrm{E}-03$ & $2.253 \mathrm{E}-03$ & $2.151 \mathrm{E}-03$ & $2.352 \mathrm{E}-03$ & $2.352 \mathrm{E}-03$ & $2.172 \mathrm{E}-03$ \\
8 & $1.465 \mathrm{E}-03$ & $1.573 \mathrm{E}-03$ & $1.355 \mathrm{E}-03$ & $1.475 \mathrm{E}-03$ & $1.475 \mathrm{E}-03$ & $1.532 \mathrm{E}-03$ \\
10 & $1.165 \mathrm{E}-03$ & $1.252 \mathrm{E}-03$ & $1.382 \mathrm{E}-03$ & $1.054 \mathrm{E}-03$ & $1.054 \mathrm{E}-03$ & $1.335 \mathrm{E}-03$ \\
12 & $1.019 \mathrm{E}-03$ & $8.790 \mathrm{E}-04$ & $9.530 \mathrm{E}-04$ & $6.720 \mathrm{E}-04$ & $6.720 \mathrm{E}-04$ & $7.170 \mathrm{E}-04$ \\
14 & $8.330 \mathrm{E}-04$ & $5.770 \mathrm{E}-04$ & $3.170 \mathrm{E}-04$ & $4.210 \mathrm{E}-04$ & $4.210 \mathrm{E}-04$ & $2.050 \mathrm{E}-04$ \\
16 & $5.240 \mathrm{E}-04$ & $5.290 \mathrm{E}-04$ & $1.410 \mathrm{E}-04$ & $3.910 \mathrm{E}-04$ & $3.910 \mathrm{E}-04$ & $2.310 \mathrm{E}-04$ \\
\hline
\end{tabular}



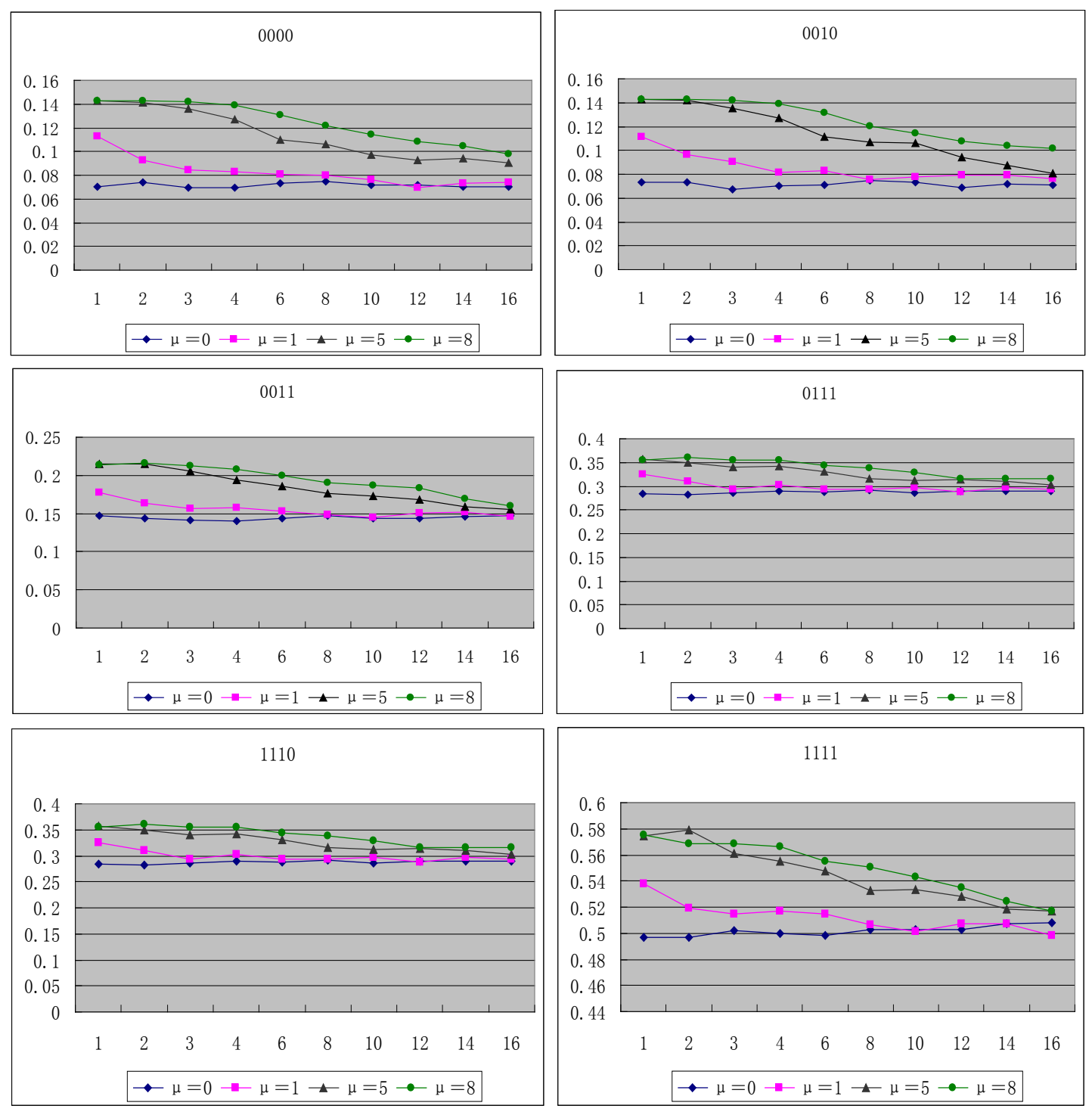

Figure 4: Effect of turbulence of the environment on the design of EC-PBO

Moreover, we do further investigation. In terms of capability of the EC-PBO, we compute performance variance under the different $\sigma$ for each of ESC-PBO respectively. The results of some typical EC-PBOs are listed at Table 3. As shown in Table 3, for all the EC-PBOs, the performance variance increases with $\mu$ from 0 to 5 , and when $\mu>5$, the performance variance begins to decrease. The results indicate that unless the EC-PBO is capable enough, it will not get stable performance with $\sigma$ increasing. Then we computed the performance variance under different capability in terms of $\sigma$ respectively for each EC-PBO. From the data of Table 4, we can see that the performance difference between the EC-PBO with different capability increases with $\sigma$ from 1 to 3 and decreases with $\sigma$ from 4 to 16 for 0000 and 0100 type of EC-PBO, and it increases with $\sigma$ from 1 to 2 and decreases with $\sigma$ from 3 to 16 for the other type of EC-PBO. This finding further illustrates that the capability of the EC-PBO has an impact on the performance only when $\sigma<3$.

To sum up, with the environment becoming more turbulent, the capability determined by non-economic factors can not help EC-PBOs maintain stable performance and might even cause performance to decline sharply. On the contrary, the role of the complement correlation among the variables is particularly evident when the environment is becoming increasingly unstable. In such cases, the EC-PBO should focus on finding out and creating the complement correlation among the organization activities rather than the capability determined by the non-economic factors. 
Wang, Hu, and Jiang

\subsection{Validation}

In the validation of model, we utilize qualitative validation method. The government investment projects are the main objects in our investigation. We collect typical cases of the EC-PBOs through the exhaustive investigation. Then we classify them according the four structure variables of the model (1). Lastly, we compare the performance of these typical EC-PBOs. As to the performance of the EC-PBO, we think it manifests itself by the overall effect of the cost of organizing and operating, the extent of reflection of the principle or owner's intention and the professional extent of the EC-PBO as the agent. Besides, we study these typical EC-PBOs' property right, whether they operate for profit, and whether they share the project savings. These supplemental investigations provide us with some supports from the other perspective too. The findings of investigation are consistent with the results of the model. So we verified the proposed model qualitatively. For the sake of space, we do not give the detailed description of validation.

\section{CONCLUSION}

The size, formalization or regularization, the form of information processing and incentive system are the main design elements or activities needed to be paid attentions to by EC-PBO of China. And the four elements are contextual. The other two factors that need EC-PBO to pay attention to are the capability determined by the non-economic factors and the turbulence of the environment. So the contextuality of the design elements, the capability and the turbulence of the environment are the main factors that have an impact on the performance of EC-PBOs. In this paper, we firstly analyze the above factors. Then we propose the organizational design model that has both the advantages of NK model and the ones of complementarity framework. Moreover, we validate the model qualitatively according to the data collected from the typical EC-PBOs cases.

From the results of the model, we can conclude that: (a) if consider the capability of EC-PBO, the results are not consistent with the universal practice or conventional wisdom. Under the stable environment, we should conduct organization design especially fro the incentive system according to the capability for EC-PBO to improve the effect of project investment; (b) in the long run, when the environment is becoming turbulent more and more, the role of the capability will be limited finally; (c) although the complement correlation is weakened by the capability of EC-PBO in the short term, it will play an important role in the development of the EC-PBO with the turbulence of the environment. Therefore more attention should be given to EC-PBOs to improve their management practices and to find out and create a situation of contextual interaction among the elements or activities of design as a means of obtaining competitive advantage.

\section{ACKNOWLEDGMENTS}

Our work was conducted in the research team for Complex Management Systems at Modernized Management Institute, School of Management, Huazhong University of Science and Technology. Our study was funded by the China National Natural Science Fund (No. 70671048) and funded as a part of research projects by the Department of Transportation of Hubei province in China (No.2007-582).

\section{REFERENCES}

Carley, K. 1994. Sociology: Computational organization theory. Social Science Computer Review 12(4):611-624.

Carley, K. 1996. A comparison of artificial and human organizations. Journal of Economic Behavior \& Organization 31(2): 75-191.

Carley, K. 2002. Computational organizational science and organizational engineering, Simulation Modeling Practice and Theory 10 (5-7): $253-269$.

Drazin, R., and A. H.Van de Ven. 1985. Alternative forms of fit in contingency theory. Administrative Science Quarterly 30 : 514-539.

Daft, R. L. 2001. Organization theory and design. Cincinnati: South-Western College Pub.

Gilbert, N., and R. Conte. 1995. Artificial Societies, the Computer Simulation of Social Life. London: University College Press.

Kauffman, S. A. 1993. The origins of order: self-organization and selection in evolution. New York: Oxford University Press.

Lamners, C. J., and D. J. Hickson. 1980.Organizations alike and unlike. Boston: Rutledge and Keegan Pual.

Levinthal, D. A. 1997. Adaptation on rugged landscapes. Management Science 43: 934-950.

Milgrom, P. R., and J. Roberts. 1995. Complementarities and fit: Strategy, structure, and organizational change in manufacturing. Journal of Accounting and Economics 19:179-208. 
Porter, M., and N. Siggelkow. 2008. Contextuality within activity systems and sustainability of competitive advantage. Academy of Management Perspectives 5:34-57.

Rivkin, J. W., and N. Siggelkow. 2003. Balancing search and stability: Interdependencies among elements of organizational design. Management Science 49: 290 -311.

Siggelkow, N., and D. A. Levinthal. 2003. Temporarily divide to conquer: Centralized, decentralized, and reintegrated organizational approaches to exploration and adaptation. Organization Science 14: 650-669.

Siggelkow, N., and J. W. Rivkin. 2005. Speed and search:Designing organizations for turbulence and complexity. Organization Science 16: 101-122.

Siggelkow, N., and J. W. Rivkin. 2006. When exploration backfires: Unintended consequences of multi-level organizational search. Academy of Management Journal 49:779-795.

Tannenbaum, A. S., and R. S. Cooke. 1980. Organizational control: a review of studies employing the control graph method.

Topkis, D. M. 1978. Minimizing a submodular function on a lattice. Operations Research 26: 305-321.

Turner, J. R., and A. Keegan. 1999. The versatile project-based organization: governance and operational control. European management journal 17(3):296-309.

Turner, J. R., and S. J. Simister. 2001. Project contract management and a theory of organization. International Journal of project management 19:457-464.

Wright, S. 1931. Evolution in mendelian populations. Genetics 16:97-159.

Wu, J., B. Hu, J. L. Zhang, et al. 2007. Multi-agent simulation of group behavior in E-Government policy decision. Simulat. Modell. Pract.Theory doi:10.1016/j.simpat.2007.07.007.

Xia, G. C., and B. Hu. 2005. Integrated qualitative simulation method for group behavior. Journal of Artificial Societies and Social Simulation 8(2)1 <http://jasss.soc.surrey.ac.uk/8/2/1.html>.

\section{AUTHOR BIOGRAPHIES}

HUANHUAN WANG is a PhD candidate in School of Management, Huazhong University of Science and Technology, P.R. China, and also is a lecturer of China Three Gorges University, P.R. China. He received M.S. in China University of Geosciences, P.R. China in 2005. His research interests include Management System Simulation, Computational Organization Theory, and Artificial Intelligence. His research papers have published in many Chinese journals. His e-mail address is

<tinawang_053101@126.com>.

BIN HU is a professor, director of Modern Management Institute, School of Management, Huazhong University of Science and Technology, P.R. China. He received M.S. in Wuhan University of Technology, P.R. China (1989 and 1994). He received the Ph.D. in Management Science and Engineering from Huazhong University of Science and Technology, P.R. China (1999). His research interests include Management System Simulation, Decision Support System and Artificial Intelligence. His research papers have published in many Chinese journals and international journals. His e-mail address is $<$ bin_hu@mail.hust.edu.cn>.

GUOYIN JIANG is a lecturer of Hubei University of Economics, P.R. China, and also is a PhD candidate in School of Management, Huazhong University of Science and Technology, P.R. China. He received M.S. in Sichuan University, P.R. China in 2004. His research interests include Management System Simulation and Decision Support System. His research papers have published in many Chinese journals and international conference. His e-mail address is <guoyin_jiang@126.com>. 